\title{
PRIJSINDEXCIJFERS EN DUURZAME PRODUKTIEMIDDELEN III
}

\author{
door Drs. B. M. Balk, Drs. L. Hoven, Drs. J. D. Lock
}

Centraal Bureau voor de Statistiek Voorburg

\section{Inleiding}

Deze aflevering bevat het derde en laatste hoofdstuk van onze bijdrage. In hoofdstuk 1 - twee afleveringen terug - werden de gangbare formules voor een prijsindex en de zgn. impliciete deflatoren besproken. De vorige aflevering bevatte hoofdstuk 2. Daarin ging het om het probleem van de kwaliteitsverandering van de in de regelmatige prijswaarneming opgenomen goederen. In dit hoofdstuk 3 geven we een opsomming en korte beschrijving van de op dit moment door het C.B.S. samengestelde prijzenstatistieken in de sfeer van de duurzame produktie. middelen.

\section{Prijsstatistieken van produktiemiddelen}

\subsection{Algemene opmerkingen}

De in de bedrijven aanwezige duurzame produktiemiddelen kunnen onderver. deeld worden in een viertal categorieën:

- grond

- gebouwen

- vervoermiddelen

- machines en overige uitrustingsstukken.

Hierbij wordt de categorie gebouwen ruim opgevat. Ook woningen en eventuele grond., water- en wegenbouwkundige werken vallen hieronder.

In principe kunnen prijsindexcijfers van deze groepen (en onderdelen daarvan) worden samengesteld bij transacties van deze produktiemiddelen. Het is nuttig hierbij onderscheid te maken tussen transacties van nieuwe en gebruikte produk. tiemiddelen.

De grond is per definitie reeds vóór de transactie gebruikt en komt alleen uit Nederland (geen invoer).

De gebouwen kunnen nieuw of gebruikt worden verhandeld. Zij zijn ook alleen uit het binnenland afkomstig.

De vervoermiddelen worden geproduceerd in de transportmiddelenindustrie of ingevoerd. Het gaat hier voor het grootste deel om nieuwe vervoermiddelen.

De machines en overige uitrustingsstukken tenslotte worden in hoofdzaak ge. produceerd in de metaalprodukten-, machine- en electrotechnische industrie of ingevoerd. Het betreft ook hier in het algemeen nieuwe produktiemiddelen.

De waardering van een transactie kan verschillen al naar gelang de plaats van meting. De af-producentwaardering heeft betrekking op het moment dat het goed de producent verlaat.

De inkoopwaarde van een duurzaam produktiemiddel is de waarde bij aan. koop. Het verschil tussen beide waarderingen wordt gevormd door de handels. en vervoersmarge. 
In de volgende paragrafen zullen we de door het C.B.S. samengestelde prijzen. statistieken voor investeringsgoederen kort beschrijven. De in paragraaf 3.4 te be handelen deflatoren daargelaten, zijn alle prijsindexcijfers berekend volgens de formule van Laspeyres.

In elk geval zullen we aangeven waar de betreffende statistiek wordt gepubliceerd. Daarbij wordt niet afzonderlijk vermeld dat veelal de cijfers in geaggregeer. de vorm reeds vroegtijdig worden gepubliceerd in het Statistisch bulletin (dat in de regel enkele malen per week verschijnt).

\subsection{Producentenprijzen}

Het C.B.S. stelt maandelijks een algemeen prijsindexcijfer van finale produkten samen. Dit betreft producentenprijzen van door de Nederlandse industrie geproduceerde consumptie- en investeringsgoederen ${ }^{9}$ ). Een onderdeel van dit prijsindexcijfer is het prijsindexcijfer van investeringsgoederen. Het gaat hier voor het overgrote deel (96\%) om goederen afkomstig uit de metaalnijverheid en om en. kele goederen uit de hout- en meubelindustrie en de textielindustrie. Dit indexcijfer wordt gepubliceerd in tabel 3.2. van de Maandstatistiek van de prijzen, ongeveer drie maanden na afloop van de maand waarop het indexcijfer betrekking heeft. In dit algemene indexcijfer zijn zowel vervoermiddelen als machines en overige uitrustingsstukken begrepen. De prijswaarneming geschiedt bij de producenten van deze goederen en de prijsindexcijfers hebben zodoende betrekking op de af.producent waarde van de goederen (exclusief B.T.W.).

Uit het voorgaande valt af te leiden dat de ingevoerde investeringsgoederen niet in dit indexcijfer begrepen zijn. Dat dit niet onbelangrijk is, volgt uit het feit dat in 1976 ruim $80 \%$ van de waarde van de geïnvesteerde vervoermiddelen in. voer betrof en dat voor de machines en overige uitrustingsstukken dit percentage bijna 45 bedroeg.

Hierbij zij aangetekend dat het C.B.S. in het jaar 1977 is gestart met een enquête naar de prijzen van ingevoerde investeringsgoederen (c.i.f. waardering). Het zal echter nog geruime tijd duren voordat prijsindexcijfers van de gehele in. voer van investeringsgoederen kunnen worden gepubliceerd.

Ten slotte moet t.a.v. dit algemene indexcijfer van investeringsgoederen worden vermeld dat schepen en vliegtuigen ontbreken.

Het prijsindexcijfer van investeringsgoederen is een gemiddelde van de prijs. indexcijfers afzet binnenland van goederen, welke als investeringsgoed geken merkt kunnen worden. Deze prijsindexcijfers worden maandelijks voor afzonderlijke goederen of goederengroepen gerangschikt naar bedrijfsklasse gepubliceerd in tabel 3.3 van de Maandstatistiek van de prijzen en in zeer gedetailleerde vorm in tabel 10.2 van het bijvoegsel.

In de appendix volgt een opsomming van de belangrijkste goederen en goe. derengroepen waarvoor producentenprijsindexcijfers beschikbaar zijn. Momenteel is het basisjaar voor deze indexcijfers 1970. Ter illustratie zijn de prijsindex. cijfers per januari 1978 erbij gezet.

Naast de in de appendix genoemde goederen behoren linoleum en viltzeil (af. komstig uit de textielindustrie) tot de investeringsgoederen en vormen de prijs-

Voor een toelichting op dit algemene prijsindexcijfer zie het arcikel „Vervanging van het indexcijfer van groothandelsprij. zen", Maandstatistiek van de prijzen, maart 1976.

$m a b \quad b l z .136$ 
indexcijfers hiervan $\left.{ }^{10}\right)$ een onderdeel van het algemene prijsindexcijfer investe. ringsgoederen.

Als gevolg van geheimhoudingsregels ${ }^{11}$ ) is het echter niet mogelijk deze partiële prijsindexcijfers afzonderlijk te publiceren.

Ten slotte bevat het algemene prijsindexcijfer investeringsgoederen enkele componenten uit de groepen timmerwerk, houtwaren en houten meubelen afkomstig uit de hout. en meubelindustrie ${ }^{12}$ ).

\subsection{Bouwkosten van woningen}

Ieder kwartaal worden prijsindexcijfers van de output van de woningbouw samengesteld. Publikatie vindt plaats in de Maandstatistiek bouwnijuerheid (tabel 9.1.a) en de Maandstatistiek van de prijzen (tabel 4.2) van prijsindexcijfers inclusief B.T.W. ${ }^{13}$ ). Er worden ook cijfers exclusief B.T.W. gepubliceerd in de Maandstatistiek bouwnijuerheid (tabel 9.1.b). Het behoeft geen betoog dat, afgezien van de B.T.W., de af producentprijzen gelijk zijn aan de inkoopprijzen. De berekening van deze prijsindexcijfers is gebaseerd op aannemingssommen van woningwetwoningen (zowel eengezinshuizen als woningen in meergezinshuizen). Ook t.b.v. de samenstelling van deze prijsindexcijfers wordt de kwaliteitsverandering zo goed moge. lijk geëlimineerd. Er worden alleen totale indexcijfers gepubliceerd, m.a.w. er worden geen uitsplitsingen naar soort woning en regio gepubliceerd. Deze index. cijfers gelden naar de mening van het C.B.S., behalve voor de woningbouw ook bij benadering voor de utiliteitsbouw, doch niet voor de weg. en waterbouwkun. dige werken.

\subsection{Deflatoren in de Nationale rekeningen}

In de jaarlijkse publikatie van de Nationale rekeningen staan o.m. waardegegevens betreffende de investeringen in vaste activa (het gaat hier om nieuwe activa). Zoals in 1.5 reeds werd opgemerkt zijn deflatoren prijsindexcijfers die gebruikt worden om uit waardetotalen in werkelijke prijzen waardetotalen in constante prijzen te berekenen. In tabel 18 van voornoemde publikatie wordt jaarlijks een prijsindexcijfer van de bruto investeringen in vaste activa van bedrijven gepubliceerd. Voor de onderdelen van dit aggregaat (investeringen naar sectoren en be. drijfstakken van bestemming en investeringen naar type van activa) worden geen prijsindexcijfers gepubliceerd.

Wel zijn in tabellen 21 en 23 waardegegevens in werkelijke en constante prijzen opgenomen, zodat de prijsindexcijfers door deling van de corresponderende waardegegevens in werkelijke prijzen door die in constante prijzen kunnen worden afgeleid.

Hierbij wordt in tabel 21 voor wat betreft de onderverdeling naar bestemming de volgende indeling gehanteerd:

- landbouw en visserij;

- nijverheid;

\footnotetext{
10 Voor een nadere toelichting op de indexcijfers van producentenprijzen van de textielindustrie raadplege men de Maandstatistiek van de binnenlandse handel, september 1974.

11) In principe dient een prijsindexcijfer op tenminste drie onafhankelijke producenten betrekking te hebben alvorens tot pu blikatic kan worden overgegaan.

12) Voor een toelichting op de indexcijfers van producentenprijzen van de hout. en meubelindustrie zie de Maandstatistiek van de binnenlandse handeh novernber 1972.

13) Voor een toelichting zie Maandstatistiek boummijuerheid, november 1964
} 
- handel;

- transport., opslag. en communicatiebedrijven;

- exploitatie van woningen;

- overige diensten.

In tabel 23 is de volgende onderverdeling naar type van activa aangehouden:

- woningen;

- gebouwen voor bedrijven en overheid;

- grond, water- en wegenbouwkundige werken;

- externe vervoermiddelen voor:

- wegvervoer (personenauto's);

- wegvervoer (overige vervoermiddelen);

- railvervoer;

- vervoer te water;

- vervoer door de lucht;

- toename veestapel (gebruiksvee);

- machines en overige uitrustingsstukken.

\subsection{Overige prijsstatistieken}

Het C.B.S. publiceert statistieken van gemiddelde prijzen van nieuwe en bestaan de woningen in de Maandstatistiek bouwnijuerheid en de Maandstatistiek van de prijzen. Omdat hiermee eigenlijk buiten het onderwerp van deze bijdrage (prijsindexcij. fers van investeringen door bedrijven) wordt getreden, gaan we hier niet verder op in.

Halfjaarlijkse gegevens met betrekking tot de gemiddelde koopprijzen van bouwgronden worden gepubliceerd in de Maandstatistiek bouwnijuerheid en de Maandstatistiek van de prizzen $\left.{ }^{14}\right)$. Hierbij wordt de navolgende specificatie gehanteerd:

- bouwgronden door gemeenten verkregen;

- bouwterreinen gekocht van gemeenten;

- bouwterreinen gekocht van derden;

- industrieterreinen gekocht van gemeenten;

- industrieterreinen gekocht van derden.

Het onderscheid naar bouw. en industrieterrein wordt gemaakt aan de hand van de hoedanigheid van de koper. Voorts wordt nog een onderscheid gemaakt naar urbanisatiegraad en naar gemeente. Voor de bouwterreinen gekocht door gemeenten en gekocht van gemeenten en van anderen worden ook indexcijfers van de koopprijzen gepubliceerd (alleen in de Maandstatistiek bouwnijuerheid).

Dit is niet mogelijk voor de gekochte industrieterreinen (vanwege de geringe aantallen). Voor de indexcijfers is geen specificatie naar urbanisatiegraad en provincie gepubliceerd. Hierbij zij vermeld dat verwacht mag worden dat deze indexcijfers niet vrij zijn van het effect van kwaliteitsverschillen.

14) Voor een toelichting zie Maandstatistiek bouwnijuerheid, september 1977 


\section{Appendix}

Goederen ( groepen) waarvoor producentenprijsindexcijfers beschikbaar zijn, met het prijsindexcijfer per januari $1978(1970=100)$. De nummering is die van het bijvoegsel Maandstatistiek van de prijzen, tabel 10.2.

\section{Metaalproduktenindustrie}

1.1 constructiewerken................................................................................. 165

1.11 reservoirs .......................................................................................... 160

1.12 gebouwen, loodsen, overkappingen en spanten ................................. 167

1.13 overige constructiewerken.................................................................... 167

3. radiatoren en ketels voor centrale verwarming ……….................... 140

3.1 radiatoren voor centrale verwarming …………................................. 162

3.2 centrale verwarmingsketels................................................................. 126

6. lampen, armaturen en lantaarns ......................................................... 154

7. uitrustingsstukken voor industriële bedrijven, e.d.............................. 159

7.1 gas en watermeters........................................................................... 141

7.2 overige uitrustingsstukken ................................................................. 163

11. pijpleidingen ..................................................................................... 176

12.6 kantoor-, kantine- en bedrijfsmeubelen................................................. 163

12.61 stoelen, zitkrukken e.d....................................................................... 159

12.62 bureau's en kantoortafels............................................................... 176

12.63 overige bedrijfstafels c.q. bedrijfsmeubelen ......................................... 160

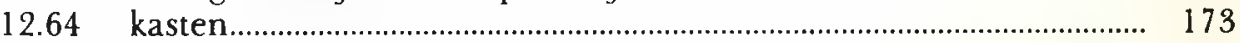

12.65 overige kantoor en magazijnmeubelen e.d. ...................................... 151

\section{Machine-industrie}

1. hijs., hef. en graafwerktuigen ............................................................. 179

1.1 hijs. en hefwerktuigen........................................................................ 178

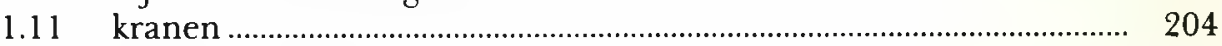

1.12 liften, roltrappen e.d.............................................................................. 163

1.12 .1 personenliften ................................................................................... 167

1.13 lieren, windassen en takels............................................................... 163

1.14 transportinrichtingen ........................................................................... 172

1.15 vorkheftrucks en zijstapeltrucks .......................................................... 151

1.16 overige hijs. en hefmachines, toebehoren en onderdelen ............... 187

1.2 delf graafmachines en toebehoren..................................................... 185

1.21 delf. en graafmachines........................................................................ 193

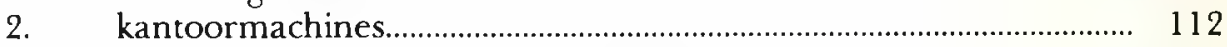

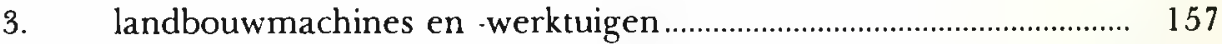

4. winkelmachines en weegwerktuigen .................................................... 222

4.2 weegwerktuigen ................................................................................... 226

5. machines en werktuigen voor de nijverheid....................................... 167

5.1 machines en toestellen voor de nijverheid.......................................... 168

5.11 voor de voedings. en genotmiddelenindustrie .................................. 161

5.111 zuivelwerktuigen .............................................................................. 150

5.112 overige voedings- en genotmiddelenindustrie ................................... 163 
5.12 chemische industrie ........................................................................... 181

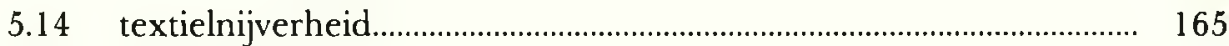

5.15 kunststoffen- en petrochemische industrie ........................................... $\mathrm{x}$

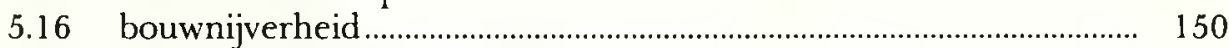

5.17 overige nijverheid en bedrijven......................................................... 171

5.2 gereedschapswerktuigen en gereedschappen ................................... 164

5.21 gereedschapswerktuigen................................................................... 162

5.212 boormachines.................................................................................. 155

5.214 slijp- en polijstmachines ..................................................................... 177

5.216 gereedschapswerktuigen voor de bewerking van metalen, stenen e.d.

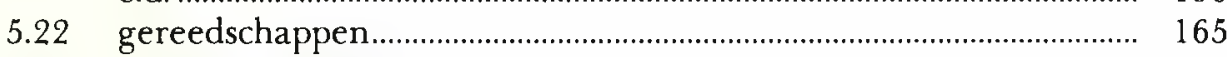

5.221 machinegereedschappn ....................................................................... 152

5.222 handgereedschappen..................................................................... 177

6. vloeistofpompen.............................................................................. 190

6.1 centrifugaalpompen .................................................................... 201

6.2 overige vloeistofpompen...................................................................... 165

7. tand- en wormwielen, koppelingen, drijfwerken en onderdelen ... 183

8. stoomketels, turbines en motoren ...................................................... 211

8.1 stoomketels, stoommachines en turbines.......................................... 208

8.12 stoomketels .......................................................................................... 195

8.2 verbrandingsmotoren en toebehoren.................................................... 223

9. appendages ..................................................................................... 162

10. luchtbehandelings- en ruimteverwarmingsapparaten ...................... 156

10.2 koel- en vriesmachines...................................................................... 155

10.4 luchttechnische apparaten, stookinrichtingen en toebehoren......... 154

11. filter- en zuiveringstoestellen ............................................................. 185

12.1 brandblusinstallaties en -apparaten........................................................ 146

\section{Elektrotechnische industrie}

2. elektromotoren, generatoren en transformatoren, schakel. en in stallatiemateriaal.

2.1 elektromotoren, generatoren en transformatoren ............................ 143

2.11 elektromotoren en generatoren .......................................................... 169

2.112 elektromotoren en onderdelen......................................................... 164

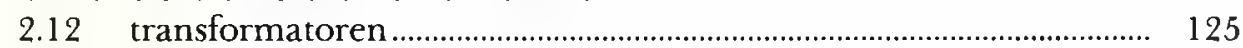

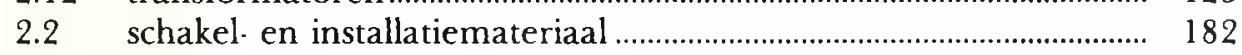

2.21 schakel. en verdeelinrichtingen .................................................... 191

2.22 installatiemateriaal (incl. kleinschakelmateriaal)................................ 142

3.3 elektrische en elektronische meet. en regelapparatuur en elektromedische toestellen.................................................................................. 148

3.31 elektrische meetinrichtingen en -instrumenten.................................. 148

3.32 medische en röntgenapparatuur ............................................................ 148

\section{Transportmiddelenindustrie}

2.2 landbouwwagens e.d. 
2.22 kruiwagens (staal) ............................................................................. 141

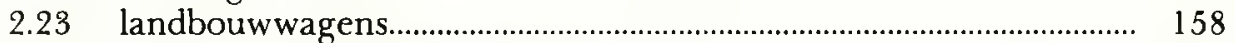

2.24 wagens voor intern transport............................................................... 164

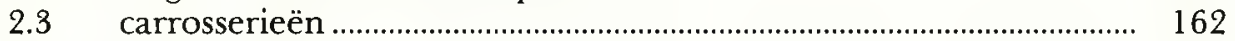

2.31 opleggers ............................................................................................ 145

2.32 aanhangwagens................................................................................. 159

2.33 overige carrosserieën …………........................................................... 165

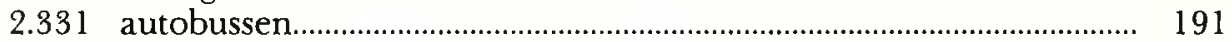

2.334 overige vrachtwagens.................................................................. 163

2.335 brandweer en reinigingsauto's ............................................................. 138

$2.4 \quad$ assemblage- en produktie-inrichtingen ................................................. 154

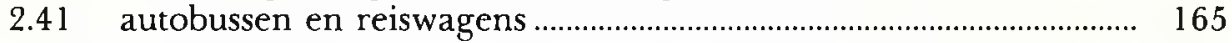

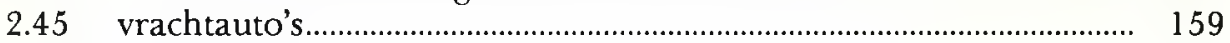

Bron: Centraal Bureau voor de Statistiek,

Maandstatistiek van de prijzen, juni 1978

Zie voor een nadere toelichting op deze prijsindexcijfers de Maandstatistiek van de binnenlandse handel, oktober 1973 (metaalproduktenindustrie), juni 1973 (machineindustrie), mei 1974 (elektrotechnische industrie) en april 1973 (transportmidde. lenindustrie). 